\section{The public's case is put}

The tortuous process of setting controls on the use of a revolutionary, but potentially hazardous, technique for manipulating genes from living organisms has entered a new and politically important stage in Washington. Colin Norman reports

For the first time, the question of controls over genetic manipulation experiments was last week opened up to allow members of various public groups to express their opinions on the risks and benefits of the research, and to influence the development of the proposed controls. The forum was provided by an open meeting of a toplevel advisory committee of the National Institutes of Health (NIH), the institution which funds the bulk of biomedical research in the United States. The meeting was called by NIH Director $\mathrm{Dr}$ Donald Fredrickson to discuss whether or not the proposed guidelines, drafted by another NIH committee last December after months of argument and confusion, should be adopted. Fredrickson will decide that question before the drafting committee next meets in April. Hanging on his decision are several exciting experiments which are currently under embargo.

The technique involves the use of a newly-discovered class of enzymes to transplant genes from one organism into another. The utility of the technique is that it enables genes from any organism, including man, to be inserted into a virus or bacterium so that they are copied by the reproductive machinery of their new host. That possibility could open up revolutionary advances in understanding how genes work and more distantly, it could lead to such applications as improving yields of crop plants and repairing genetic diseases.

But, in 1973, scientists involved in the research began to express concern about the fact that the technique allows genes to be shuffled between species and joined in combinations which are unlikely to have occurred by evolution. It is conceivable, for example, that a virus or bacterium bearing transplanted genes could be endowed with unpredictable biological properties so that, in the worst imaginable case, a novel epidemic could be let loose if they escape from the laboratory. Such concerns led a committee of the National Academy of Sciences, chaired by Paul Berg of Stanford University, to urge in July 1974 that a laboratory. moratorium be placed on some uses of the techniques until the hazards are assessed. That call was followed early last year by an international meeting of geneticists to discuss the hazards; since then, the NIH committee has been attempting to draft regulations to control the technique.

Last week's meeting provided a confused discussion which resulted in conflicting advice being given to Fredrickson about the acceptability of the proposed regulations. The committee, which consisted of scientists, lawyers and lay members, listened to statements from those who drafted the regulations and from a variety of groups and individuals, on the basis of which each member will provide Fredrickson with views on whether or not the proposed controls are acceptable. The fundamental issue is whether, and under what conditions, some of the research which was placed under a voluntary moratorium by the Berg committee's appeal should be allowed to go ahead.

The proposed controls would allow some of the research to be resumed, but under very strict conditions. Essentially, the controls specify that most experiments should be performed in laboratories especially equipped with safety devices--in much the same way that research involving hazardous pathogens is now performed-and, in addition, genes should only be transplanted into organisms which have been crippled in such a way that they would be incapable of surviving outside the

Berg himself said last week that he believes that the proposed controls are "stricter than necessary to protect public health", but added that he believes that it is better to err on the side of caution. Similarly, Dr Roy Curtiss, a microbiologist from the University of Alabama, told the committee that he believes the proposed controls are sufficiently strict to guard against the possible hazards. He also announced that he has constructed in his laboratory a strain of the common intestinal bacterium $E$. coli, which appears to have been mutated so as to be incapable of surviving outside an artificial laboratory environment. E. coli, the geneticists' workhorse, is the most likely host for transplanted genes.

But a few scientists expressed the opinion that the proposed guidelines are too strict, and will greatly restrict an exciting and potentially beneficial area of research. Dr David Hogness, a member of the committee which drafted the proposed controls, for example, suggested that there is little evidence that the speculated hazards are real, and argued that "in the present climate of opinion, the benefits of increasing knowledge have been underemphasised". And Dr Donald Brown, a geneticist who has been using the technique to grow and purify frog genes in $E$. coli, suggested that the controls are so strict as to be totally irrational.

On the other hand, several other witnesses, most prominently members of a group of radical scientists called the Boston Area Recombinant DNA group, argued that many planned experiments should be delayed, at least until the hazards have been evaluated. In particular, they urged that $E$. coli should not be used as the host for transplanted genes because that bacterium is a common inhabitant of the human gut.

Dr Allen Silverstone, a spokesman for the Boston group said, for example, that "unless we can be assured that the possibility of danger is reduced to insignificance, we would suggest that the NIH withold funding such research, until the questions of safety and procedure are settled, especially to the satisfaction of honest critics within the scientific community and the public. We do not propose this lightly. We recognise that many scientists wish to do these experiments, and thus far their restraint has been admirable."

Faced with those conflicting views, Fredrickson must soon decide whether or not to accept the proposed controls or suggest that they should be modified. If he does suggest modifications, it is likely that he will require that the drafting committee should pay more attention to devising ways in which the proposed controls should be implemented.

The proposed guidelines, which would apply only to research funded by NIH, suggest that implementation of the controls should largely be left to institutional committees, which would ensure that the safety precautions at institutions where experiments will be undertaken, meet conditions set out in the regulations.

It should be noted that, by providing public input into his decision, Fredrickson has drawn the sting from a common criticism that the process has lacked participation from people outside the scientific community. Senator Edward Kennedy, for example, has suggested that such matters are too important to be left solely to scientists, and he would presumably be ready to provide such input by legislation if necessary. Last week's public meeting should at least guard against the research being regulated by legislation. $\square$ 